\title{
DIGITALCOMMONS
}

@WAYNESTATE -

\section{Sociological Practice}

Volume 7

Issue 1 The Development of Clinical and Applied

Article 20

Sociology

January 1989

\section{Ethical Limitations on Sociological Reporting}

Joseph H. Fichter

Loyola University

William L. Kolb

Tulane University

Follow this and additional works at: http://digitalcommons.wayne.edu/socprac

Cart of the Sociology Commons

\section{Recommended Citation}

Fichter, Joseph H. and Kolb, William L. (1989) "Ethical Limitations on Sociological Reporting," Sociological Practice: Vol. 7: Iss. 1, Article 20.

Available at: http://digitalcommons.wayne.edu/socprac/vol7/iss1/20 


\title{
Ethical Limitations on Sociological Reporting
}

\author{
Joseph H. Fichter \\ Loyola University \\ William L. Kolb \\ Tulane University
}

In his primary task as the discoverer of new knowledge, the modern scientist is governed by the obligations to search for truth, to be objective, to discern the relevant, to check meticulously his data, and, in some circles, to accept responsibility for the use to which his knowledge is put. This ethical code, however, fails to cover the problems arising from the relations between the scientist and the objects of his observation and experimentation. This may be due in part to the very conceptualization of phenomena as "objects." Only "subjects" have rights which must be respected.

There is evidence, of course, that social scientists are vaguely aware that they incur responsibilities which extend beyond the procedural ethics of science itself: that men are subjects as well as objects and that even when studied as objects they retain certain of their rights to privacy and respect. Thus the experiments on living human bodies of prisoners, made by Nazi doctors, gained them infamy rather than fame. The theoretical literature of American psychiatry hides the identity of most of its patients. And sociologists and anthropologists frequently attempt to disguise the communities they study.

The lack of consensus in this area of responsibility attests to the fact that the norms underlying such efforts to respect people who are studied have never been systematically formulated as part of the procedure of scientific research and reporting. Indeed individuals and groups receive the greatest protection when scientific research is linked with the doctor-patient relation as in the case of psychiatry. In other areas protection seems to depend upon a diffuse and uncertain feeling of respect for the human "object." This protection is

Reprinted from American Sociological Review, Vol. 18, No. 5, October, 1953, pp. 544-550. 
adequate, however, only where it does not interfere seriously with the gathering and reporting of data or where its violation would take such extreme form as to severely shock both the scientist and his society.

Under present conditions, the possibility of disturbance and shock seems greatest where research and reporting directly involve identifiable small groups and individuals. Research workers also seem to be effectively barred from experimentation which threaten the physical wholeness of the individual. Beyond these areas of investigation every research worker seems to be largely on his own in determining what research shall be conducted and what report shall be made so far as the impact of the research and the report on the objects of the study are concerned.

In this state of normlessness even the individual and the small group can be threatened if the possibility of identification is only indirect or if the violation of rights is not obvious and flagrant. Thus men may not be plunged into freezing water involuntarily, but children have been placed in authoritarian situations to discover the effects on their attitudes and behavior. Sexual relations between husband and wife cannot be observed by the family sociologist, but other forms of private behavior have been observed and reported. The psychiatrist will guard the identity of his patient, but the student of a community may report behavior on the part of an individual who can be indirectly identified by other members of the community or by other people in the larger society.

Although the psychologist and the social psychologist face ethical problems in experimenting with human beings, the sociologist seems most vulnerable in his studies of small groups and communities. His problem, since he does not often experiment, seems to be the question of whether there are ethical limitations on the "complete" objectivity of a research report concerning such groups and communities, for it is in this area of research that there are signs that the ethical sense of the sociologist is either dormant or only intermittently and uncertainly active. An explicit code of ethics which will govern the social scientist in reporting such data seems urgently needed.

In attempting to develop a system of relational ethics the sociologist must remember that while the people he studies have rights, these rights cannot be secured by an unqualified assertion of the "subject" status of his objects of investigation. It is an obvious absurdity to assert that these "subjects" are entitled to absolute anonymity, privacy, and protection, for in various circumstances the sociologist may be obligated to describe in full detail the actions of identifiable groups and individuals. Moreover the development of a code of ethics will not relieve the sociologist of moral choice, but can serve only as a guide for the making of decisions for which he must accept responsibility. Having said all this, however, it remains true that sociologists need to formulate a system of ethical norms to protect the objects of sociological reporting. It is as a tentative statement of the conditions relevant to such norms and of a 
few of the most important norms themselves that the following discussion is offered.

Before presenting our conception of some of the important normative variables in the formulation of such a system of ethics, it is necessary to consider first the matrix of conditions into which the system must be placed. Two aspects of this matrix seem particularly important. The first of these has to do with the various groups of people to whom the reporting sociologist has obligations; the objects of the study are only one such group. The second aspect concerns the fact that even in community and small group studies certain kinds of data and certain modes of data presentation pose the ethical problem in its most intense form, while other data and modes of presentation offer only minor problems. It is necessary to distinguish these factors, since, as scientists, maximum freedom is desirable and hence no needless restrictions are in order.

In preparing a research report on a small community or group the sociologist has a moral duty toward several different groups. Because his obligations to each of these differ in kind and degree while at the same time they condition and limit one another, it seems necessary to set forth briefly the categories into which they fall.

1. For practical, as well as moral reasons, the sociologist must consider the wishes and needs of those persons who have allowed, invited, sponsored, or cooperated with the study. Management of a factory group, officers of a labor union, ministers, and city officials, are all examples of people who may have some concern for the results of sponsored research. The sociologist's obligations to such persons are truthfulless, the honoring of confidences, scientific objectivity, and honest reporting.

2. The sociologist has obligations to the source from which research funds were obtained. Like anyone who enters a contractual agreement, he has the ordinary obligations to employ these funds honestly and usefully, and to abide by the terms of the agreement concerning publication and ownership of data, and by any other explicit provisions which might have been incorporated in the contract.

3. The publisher of the research report has a call upon the moral consideration of the sociologist. Again the obligations are derived from the ordinary desirability of honesty and thoroughness, or from legal rights relating to libel suits and other embarrassments in which the report may involve the publisher.

4. Social scientists in general may be said to have a claim on the findings of the social researcher. The scientist's colleagues have a moral expectation that the findings will be made available to them in a serious, honest, and competent report. In addition to these expectations which do not differ much from expectations of professionals in other areas of work, there are the specifically scientific demands for a free exchange of data and knowledge unhindered by secrecy and suppression. 
5. Another kind of group has a similar claim, perhaps not on the individual scientist but certainly on the discipline, to receive the findings of social research. In the long run this group is the society itself, for it is particularly important that social science knowledge ultimately become the possession of all the people. If there are reasons for the holding back of research findings from the general public for a short time, this group will still contain, at a minimum estimate, the key persons in a community or group who are in a position to utilize the research findings in programs of social improvement. The sociologist himself must bear the responsibility for determining who these persons are, unless they are defined by legal norms of the community of which the social scientist himself is a member.

6. Against the claims of all these groups on the findings of the sociologist, there exist the rights of the community studied, its subgroups, and its individual members. Their rights to secrecy, privacy, reputation, and respect, will vary according to circumstances and to the demands of the other groups, but they are intrinsically present-a society like our own which in its central tradition accords dignity and worth to the individual. The sociologist has not discharged his duties when he has met his obligations to sponsors, fund sources, publisher, social scientists, and the general public; nor has he completely discharged them when he makes a perfunctory effort at disguise, ambiguity, or anonymity. He is always faced with the moral problem of how much to tell about the lives and habits of the members of the community or small group.

The problem varies in its intensity, however, with the kind of data and with the mode of presentation. It seems obvious that historical material allows more latitude for reporting than contemporary material. Every study of a small group or community seems to require a brief sketch of historical background, and through this research the scientist may discover certain skeletons in the closet. Their revelation may be pertinent to the understanding of the group and will probably not intrude too greatly upon the community's or its individuals' reputations.

Within the area of contemporary material a distinction can be drawn between studies of primitive societies and civilized communities. It is supposed that the details of social life among the Samoans were not reported to these people, and if any reputations suffered from such study it was only among non-Samoans. There have been instances, however, of anthropologists' reports getting back to American Indian tribes, causing some dissension and suspicion among the members of the tribe. In either case the sociologist must consider these people as the subjects of human rights, even though the prospect of moral damage may not be great.

In studying contemporary communities the problem of reporting varies according to whether the data concerned are sacred or non-sacred. The analysis of behavior patterns which involve high traditional values (like religion, family 
and sex, ethnic and group loyalties) should, of course, be as objective as possible, but an effort should be made to avoid needless and callous affront to the people who hold such values and such an effort requires special attention and care. In non-sacred areas (such as economic and political activities, housing and recreational problems) there can be greater freedom of reporting.

A related and equally important distinction must be made between public and private facts. This is something more than the difference between hidden and open knowledge. By definition, the sociologist deals with social and group relations. Hence, in a sense, his data can rarely concern completely private and secret activities. Nevertheless it is obvious that widely-known facts allow a much wider margin of expression in the research report.

The manner of presenting the data may be equally important as the kind of data presented in increasing or lowering the intensity of the moral problem of what to report in a community or small group study. Although the custom of sociologists of providing anonymity to the community, group, or individual is not an adequate safeguard of the rights of these subjects, it does make possible a wider margin of expression than would a complete and open identification. There are, however, other and more important differences of mode of presentation.

The happiest situation for the social scientist is one in which statistical analysis of, and reporting on, the actions and characteristics of people is possible. Where large numbers of people are involved it is obvious that the problem of ethical limitations on the report hardly exists. But even in communities where situations are revealed that may be somewhat distasteful, the sub-groups and the individual may be adequately protected by the use of statistical categories.

As soon as the sociologist leaves the field of quantitative analysis and attempts to describe in conceptual terms the social relations in a small group or community, the problem of what to report becomes much greater. Even when the community is cloaked in anonymity, indirect identification is almost always possible, and there is likely to be a subtle and unintended violation of human rights. The threat becomes even greater when the sociologist adds to his description of the social relations in the group or community an interpretation of the motivation which supports these relations and other social behavior. Thus, where systematic sociological description and interpretation of motivation combine, the sociologist faces the gravest moral challenge, and particularly so where this mode of description and analysis is applied to a leading member of the group. The likelihood that such a person will be identified and his social behavior and personal reputation placed under scrutiny by his fellows on the basis of the research report is very great. Here, more than anywhere else, the sociologist must take care not to needlessly injure another human being.

The problem of truth telling thus becomes a circumstantial one. This means that while telling the truth cannot per se be wrong or harmful, the ethical 
question of whether or not to include a certain objective fact always arises in relation to person and circumstances. Thus complete objectivity, or telling all the truth in all circumstances, is not necessarily a morally good act.

This is true for several reasons. The researcher is, of course, bound to secrecy where information has been given in confidence or where he has made promises of secrecy. At the same time, as a scientist, he will discover natural secrets, which by their seriousness demand silence on the part of the reporter. There is also the problem of detraction-the injury of another's reputation by revealing what is detrimental but true about him. If the harmful fact is already widely disseminated or if the subject is mistaken in the belief that the fact will result in the impairment of his reputation, the sociologist may not have any obligation to conceal the fact. Otherwise its revelation is a serious matter.

In summary, it can be said the problem appears in its most intense form when some member of a community or group is singled out for description and analysis and where such description and analysis may result in the revealing of secrets, the violation of privacy, or the detraction of reputation. Placed in this situation the sociologist must evaluate the claims of the individual, or of the sub-group and community, in their relations with the claims of the research sponsors, the donors of funds, the publisher of the report, the expectations of colleagues, and the rights of the larger society. We suggest that if the researcher accepts the values of human dignity and worth and does not want needlessly to injure the objects of his investigation, he will take the following four variables into account in attempting to arrive at a decision.

1. The sociologist's definition of the nature of science. Some positivists seem to regard science only as a fascinating game played according to a set of rules.* It is doubtful that the sociologist using this conception of science may ever legitimately overrule the rights of the people studied. The simple wish of the people to conceal certain aspects of their behavior must then be considered sufficient to bar the report of that behavior.

If one regards science as a search for truth as an end to itself, the demands of the objectivity of science will carry much weight in the decision to publish all pertinent data. Except in history, however, the truth for which the social scientist searches is nomothetic, not idiographic, truth. It may be necessary to base generalizations on certain idiographic items, but man has the entire span of his career on earth to discover and disclose such items. Certainly a particular item of current behavior turned up in a community study need not be used to support a generalization if such use inflicts injury on the people being investigated.

* "Science after all is one of the games played by the children of this world, and it may very well be that those who prefer other games are in their generation wiser." Carroll C. Pratt, The Logic of Modern Psychology, New York: The Macmillan Co., 1939, p.57. 
There is a third conception of pure science. Social scientists may believe that science is both a rigidly ruled game and a search for truth which is valuable for itself, but they usually also believe that science well developed and used by experts or disseminated among the people can make for a better life. There is a sense of urgency about accomplishing this mission of pure science in the modern world. Thus, within this perspective, considerable pressure arises to ignore the rights of people who are scientifically studied. Despite this pressure it remains true that a wilful disregard for the rights of persons and groups to their privacy, reputations, and secrets, will tend to destroy the very values which the scientist hopes his basic research can render more achievable.

Frequently the scientist makes a community or small group study not as a pure scientist but in one sense or another as an applied scientist. He may carry on the research for what he himself considers desirable practical ends; he may be employed by officials of the community or group or by those of the larger society; or he may be employed by some private group with a specific selfish or altruistic interest. In all three of these instances there is pressure to report all the significant findings even though injury may be done to the objects of the study. Nevertheless the sociologist must abide by the rule that he exercise every effort to determine whether or not the values to be implemented by the study, and the probability of being able to achieve them through the use of its findings, justify the harm done to the members of the community or group.

Preoccupation with applied science is frequently accompanied by the temptation to look for and publish data which will further the realization of what the researcher himself regards as the good society or community. He is likely to believe that all of his data must be revealed in all circumstances. It appears to us that a scientist of this persuasion is most in need of the virtues of tolerance, compassion, and love, because he is in danger of placing the considerations of the "good" society above all consideration of individual rights and injuries.

The hired scientist, moreover, cannot avoid responsibility for revealing data injurious to individuals and groups by pleading loyalty to community or nation or by indicating his contractual responsibilities to a private group. Loyalty to community or nation may require injury to individuals and groups, but in such cases the scientist shares whatever guilt is incurred with all other responsible agencies. In instances of purely contractual research the scientist must accept full responsibility, because loyalty to nation or community is not involved. He is free to refuse the job, and if the values of the employing group are wrong or do not justify the amount of injury done the scientist must accept the moral responsibility.

2. Determination of the extent to which a person or group will be injured by the publication of data concerning their behavior. Those instances in which the scientist can foretell with certitude that serious injury will be done to the objects of his study seem to be very few in number. It is also likely that the 
largest proportion of his data will be free of possibly injurious materials. It is the in-between area of probable injury that is most difficult to determine and yet which must be determined.

To know what the effect of exposing a group's secrets will be, to realize how seriously a person's reputation may be damaged, and to visualize the effects of violation of privacy presupposes knowledge on the part of the scientist which he may not have. This knowledge can be approached to the extent to which the scientist saturates himself in the social relations of the group which he studies. It probably cannot be achieved by the aloof scientist who simply culls the reports of those who have done the actual and basic data collecting.

Since there is a great difference between imaginary and objective derogation of reputation, the sociologist may tend to brush off the former as relevant and uncontrollable. Human decency, however, would seem to require that the scientist make an effort to inquire even into this possibility of psychological and subjective injury. The scientist cannot guard against all such contingencies and against the unexpected and unwarranted complaints of people, but he should do his human best to avoid them ahead of time and to be sympathetic to them if they come.

If the sociologist attempts to interpret the social behavior of the people he studies, he must assess the responsibility of the people for their own actions. False sentimentality must not result in the denial of the fact that a person must accept the consequences of the acts for which he is responsible. The scientist cannot erase the responsibilities, duties, and obligations, of the objects of his study. Yet, at the same time, he must recognize that the human being is never completely responsible for his actions, and that in many cases factors over which the person or group has no control may come close to completely determining certain acts. Since the assessment of responsibility will be contained in the research report, injury can be done if the assessment is not carefully made.

3. The degree to which people or groups are actually members of a moral community of which the scientist is also a member. At the core of the Western value system is a belief in the basic dignity and worth of the human being. This belief is based on different assumptions according to the particular stream of tradition in which one locates it: the Fatherhood of God, natural law, universal human needs and aspirations, or human reason. Whatever the base, the belief implies that men are bound to one another in a moral community. Membership in this community requires that the individual's rights to privacy, secrecy, and reputation be respected, even though the human beings studied may not be members of the sociologist's own society.

The belief also implies that a man or group can renounce membership in the moral community by choosing modes of action which violate these basic values of dignity and worth. In mid-century it seems probable that men like Hitler and Stalin, organized groups like "Murder Incorporated," the Ku Klux Klan, and 
some others, have placed themselves outside the moral community and have surrendered the protection of its norms. Thus the social scientist need have no qualms about reporting in full detail the activities of such groups and people. Although this norm has never been explicitly formulated, it has guided a great deal of the research and reporting in social science.

Yet the decision of the sociologist to place particular persons or groups outside the moral community involves great responsibility, and he must be careful that his criteria of judgment permit tolerance, compassion, and wisdom. This is especially the case when he studies "unpopular" racial, religious and political groups, prostitutes, homosexuals, drug addicts, and the psychologically ill, the poor and powerless. It is hardly questionable that these people remain members of the moral community and hence retain their rights of privacy, respect, and secrecy. The needs of the society may require a limitation of their rights by the courts or by the social scientist in his reporting, but basic rights can be limited only to the extent that they must be limited. Beyond that point such people must be treated in the same way as other members of the moral community.

The recognition of basic human rights which accompany membership in the moral community is an important means by which social scientists can avoid the dangers of the use of purely subjective criteria. Within the consensus of the Western tradition it is objectively true that there are moral evils and modes of action which place the perpetrator outside this community. We must know as much as possible about such people and the scientist need have little inhibition in the report he provides about them. All other persons and groups, no matter how personally distasteful to the scientist, seem to require the respect of their fellow-members in the moral community.

4. The degree to which the larger society, the local community, or the group, needs the data of the research. Real urgency must be defined in terms of the pressing needs of a group, community, or society, or in terms of some impending problem of which the scientist but not the group or community being studied is aware. Rights and duties are never qualified in society and one of the qualifications seems to be that the society sometimes has a prior right to information which is necessary and useful for itself even though it may be harmful to an individual or sub-group.

The social scientist may find himself in one of several moral situations when he is trying to determine whether or not the social need is greater than the individual or group right. If the duly appointed authorities of a community or of the larger society believe certain information to be vitally needed, there is a prima facie case for the scientist to reveal such information. However, these authorities must show to the scientist the ground for the need. If he does not know and cannot find out from the authorities whether there is an urgent need for certain data which will be harmful to individuals and sub-groups, he is free 
of moral obligation to reveal it. If he is certain that the information is not necessary, he may in good conscience refuse to reveal it even though the authorities demand to know it. It must be recognized that his freedom in such instances is moral and not legal, and he may have to pay a price for his refusal.

In a similar manner the obligations which the scientist has to the group studied may require the revelation of information damaging to individuals or sub-groups. In this instance the scientist himself is likely to be the best judge of the need for his data. If he understands and accepts the basic values of the group and takes his obligation to the group seriously, he may find it imperative to disclose such information. Since he cannot plead ignorance, and since there is no demand from competent higher authority, the responsibility for the assessment of urgency rests squarely on the scientist.

Finally, even though neither the higher authority nor the representatives of the group studied place any demands upon him, he may become aware of facts which are vitally needed by the social group studied or by the society. In such cases he must not only accept the responsibility for violating the rights of individuals and groups, but also must arrive at his decision with very little outside aid. In clear-cut instances where the comparison and balancing of the rights of the various claimants can be easily accomplished, the decision may be easily reached. But it is certainly in this area that the researcher will be forced to consider most thoroughly the importance which he, himself, has placed on the value of the information in its relation to the needs of the group.

The complexities exhibited in the discussion of the four central variables indicate that the problem of ethical limitations on sociological reporting cannot be reduced to a simple either-or proposition of a conflict between the scientific objectivity of a research report and the ethical inhibitions of the person who writes the report. It is apparent that the sociologist must act simultaneously according to a highly developed procedural code for scientific reporting and a code of ethics based on the belief that the objects of his study are also subjects. These codes are not irreconcilable, but the resolution of specific conflicts between them may be a very complex task, involving the claims of many groups and the interrelationships of the four variables. Yet the sociologist must resolve them. If there is a tendency for the sociologist to become more scientific, he must also become increasingly sensitized to the rights, feelings, and needs of the people he studies. Treating them as subjects means that to the best of his ability he will treat them with justice, understanding, compassion, and, in the last analysis, love. 